DOI: https://doi.org/10.30749/2594-8261.v2n1p153-168

\title{
IMPACTOS ECONÔMICOS DO DESASTRE DA SAMARCO'
}

\author{
ECONOMIC IMPACTS OF THE SAMARCO DISASTER
}

\author{
Fabiano Martins Carvalho dos Santosii \\ Hugo Almeida Carlos Satiroiii \\ Paulo César Encarnaçãoiv \\ Maria Geralda de Mirandav
}

\begin{abstract}
Resumo: Este estudo buscou verificar o modo pelo qual a catástrofe ambiental provocada pela Samarco impactou as atividades econômicas das regiões mais afetadas, como Mariana, em Minas Gerais. Os dados para o estudo foram buscados em instituições públicas e privadas, como no Ministério do Desenvolvimento, Indústria e Comércio Exterior, MDIC, Departamento Nacional de Produção Mineral, DNPM, Instituto Brasileiro de Geografia e Estatística, IBGE, Bolsa de Valores de São Paulo, BOVESPA, Companhia Vale do Rio Doce (CVRD) e Instituto Brasileiro de Mineração, IBRAM. Primeiramente, foi apresentado um breve histórico da mineração nos âmbitos local e nacional e a seguir fez-se uma análise da participação econômica da atividade mineradora em nível nacional e em nível local. Por fim, após a apresentação de dados, realizou-se uma discussão, a partir de Ignacy Sachs (2002), que mostra que a miopia do lucro, que enfatiza os ganhos em curto prazo, foram os responsáveis pelo desastre e que tal prática precisa ser fortemente combatida, pois acaba por menosprezar aspectos socioambientais tão importantes quanto os financeiros, desconstruindo toda a relevância econômica da atividade alcançada ao longo dos anos.
\end{abstract}

Palavras-Chave: Mineração. Barragem de Rejeitos. Vale. Meio Ambiente.

\footnotetext{
'Artigo publicado no livro "Dossiê Mariana: O Desastre Ambiental que o Brasil não pode esquecer" com o título "Desastre da Samarco: Impactos Econômicos".

ii Professor no Instituto Federal do Paraná. Mestrando em Desenvolvimento LocaL na Unisuam. Possui graduação em Sistema de Informação pelo Centro Universitário da Cidade (2004). Tem experiência na área de Ciência da Computação, com ênfase em Engenharia de Software e Gestão de Projetos.

iii Mestre em Desenvolvimento Local, MBA em Estratégia Empresarial e Inteligência Competitiva, Pós - Graduado em Marketing Estratégico e Graduado em Turismo. Professor de Turismo e Hotelaria SENAC/RJ e Consultor de Negócios Sociais.

iv Possui graduação em Biblioteconomia e Documentação pela Universidade Federal Fluminense (2004). Tem experiência na área de Educação, com ênfase em Apoio ao Ensino-Aprendizagem do Instituto Federal Fluminense, campus Itaperuna. Concluiu o Programa de Mestrado Profissional em Desenvolvimento Local pelo Centro Universitário Augusto Motta - UNISUAM.

$\checkmark$ Mestre em Literatura Comparada com ênfase nos estudos culturais pela Universidade Federal Fluminense (UFF) e Doutora em Letras com ênfase em estudos pós-coloniais, também pela UFF. Professora do Programa de Pós-Graduação em Desenvolvimento Local, do Centro Universitário Augusto Motta, UNISUAM.
} 
Abstract: This study aims to verify the way in which the environmental catastrophe provoked by Samarco impacted the economic activities of the most affected regions, such as Mariana, in Minas Gerais. Data for the study were sought in public and private institutions, such as the Ministry of Development, Industry and Foreign Trade, MDIC, National Department of Mineral Production, DNPM, Brazilian Institute of Geography and Statistics, IBGE, São Paulo Stock Exchange, BOVESPA, Companhia Vale do Rio Doce (CVRD) and the Brazilian Mining Institute, IBRAM. Firstly, a brief history of mining was presented at the local and national levels and an analysis was made of the economic participation of the mining activity at the national and local levels. Finally, after the presentation of data, a discussion was made, based on Ignacy Sachs (2002), which shows that the myopia of profit, which emphasizes short-term gains, was responsible for the disaster and that such practice needs to be strongly opposed, since it ends up neglecting socio-environmental aspects as important as financial ones, deconstructing all the economic relevance of the activity achieved over the years.

Keywords: Mining. Reject Dam. Valley. Environment. 


\section{INTRODUÇÃO}

Desde a fundação da Companhia Vale do Rio Doce, CVRD, em 1942, que a indústria do ferro no Brasil tem contribuído fortemente para a economia brasileira, constituindo-se em elemento importante para o seu desenvolvimento. Este artigo discute alguns dados macro e microeconômicos vinculados à atividade de mineração no Brasil (principalmente de ferro) e seus impactos decorrentes do desastre ambiental ocasionado pelo rompimento da Barragem do Fundão, da empresa Samarco, associada da Vale, em 5 de novembro de 2015, em Mariana, Minas Gerais.

Tal tragédia, ocasionada pelo rompimento da Barragem do Fundão, causou prejuízos incalculáveis ao meio ambiente, matou mais de 15 pessoas e deixou quase 700 desabrigadas. É necessário destacar que entre os anos de 2011 e 2015, a Samarco recebeu diversas premiações, como "melhor e maior mineradora" ${ }^{1}$ do país, momento em que sua produção aumentou $15 \%$ e chegou a 25 milhões de toneladas de minério de ferro.

Muita produção, muito lucro, muito rejeito, precárias barragens... Pouca atenção ao meio ambiente e aos pactos do desenvolvimento sustentável. Os dados levantados durante o estudo mostram que, no período anterior à tragédia, a Samarco exportou US\$ 1,85 bilhão, o que corresponde a $1,15 \%$ do total de exportações do Brasil, sendo responsável por mais de $15 \%$ do minério de ferro exportado.

O problema é que o tal desenvolvimento sustentável, tão falado nos últimos anos, foi embotado pelo lucro rápido da Samarco, que está longe de ser uma boa empresa neste quesito, conforme julgou a revista Exame, no momento de sua premiação. Os seus dirigentes não se preocuparam com os problemas estruturais de sua barragem de rejeitos (leia-se, aquilo que não se transformou em lucro),

\footnotetext{
${ }^{1}$ A Samarco foi eleita pela quinta vez, sendo o terceiro ano consecutivo, a melhor mineradora do Brasil pelo anuário "Melhores e Maiores" da Revista Exame. A Companhia destacou-se ainda como a segunda maior do setor, ocupou a $28^{\mathrm{a}}$ colocação entre as maiores indústrias e a $10^{\mathrm{a}}$ colocação entre as principais exportadoras do País. A cerimônia de premiação foi realizada em São Paulo. (SAMARCO..., 2015).
} 
desprezou vidas humanas, destruiu por completo um povoado (Bento Rodrigues) e causou prejuízos incalculáveis ao ambiente, sobretudo, à Bacia do Rio Doce.

\section{BREVE HISTÓRICO}

Antes de adentrar a problemática propriamente dita do trabalho, faz-se necessário historicizar alguns aspectos relacionados à atividade de mineração no país, passando pelo período inicial, e mais precário, até os dias atuais com a predominância do minério de ferro.

O início da atividade de exploração mineral no Brasil remete ao século XVIII e foi inicialmente realizada com mão de obra escrava e técnicas precárias. Depois de quase dois séculos do descobrimento e de várias décadas de crise econômica e financeira na Metrópole e na Colônia, os portugueses começaram a explorar metais preciosos. Na virada do século XVIII, o desequilíbrio da balança comercial entre Portugal e Inglaterra foi, por muitos anos, compensado pelo ouro e metais preciosos levados do Brasil. (FAUSTO, 2010, p. 99). A parte e ficou em terra brasileira também contribuiu com o desenvolvimento, quando o país ainda não era independente.

Conforme Silva (1995, p. 3), no início do século XVIIII, D. João VI buscou investimentos junto a organizações inglesas, que trouxeram novas tecnologias, principalmente para a extração de ouro com processos hidrometalúrgicos. Como também foram responsáveis por grandes mudanças na implantação da extração do metal por coloração e em seguida por cianuretação. Nesse processo de modernização, foi criada a primeira empresa de mineração no Brasil, a Sociedade Mineralógica de Passagem, com objetivo de dar continuidade à lavra da camada aurífera que mergulhava na margem direita do ribeirão do Carmo, em Mariana, Minas Gerais.

O ciclo econômico do ouro foi marcado por ações de grande agressão ao meio ambiente, pois nesse período a atuação governamental era nula quanto ao controle e prevenção de danos, porém profícuo na arrecadação de impostos através do Quinto. (SILVA, 1995, P. 2). Em 1934, ocorreu um novo marco, a criação do Departamento Nacional de Produção Mineral, DNPM. No período da Segunda 
Guerra Mundial, houve reposicionamento estratégico em relação à mineração, que passou a ter especial relevância. A economia foi afetada pelas dificuldades de importação de combustível, o que gerou a urgente necessidade de se investir na produção de carvão. Pelo lado da exportação, o Brasil foi beneficiado pela demanda dos países em guerra, por insumos minerais brasileiros, como manganês, quartzo, scheelitas, monazitas... (Silva, 1995, p. 4).

Durante o período da Segunda Guerra, período em que Getúlio Vargas governava o Brasil, o acontecimento mais relevante para o país foi o acordo de Washington, pelo qual entre outras ações, foram destinados recursos para abertura de mina na bacia do Rio Doce; construção da Companhia Siderúrgica Nacional, CSN e da Companhia Vale do Rio Doce, CVRD, e, ainda, destinação de recursos para implantação de um terminal marítimo e modernização de ferrovias. (VALE, 2012, p. 41).

Considerada uma grande vitória para a mineração, em 1961, foi criado o Ministério das Minas e Energia. Em 1967, foi publicado o Código de Mineração, que significou um grande avanço sobre os princípios do antigo Código de Minas. O Código de 1967 retirou do proprietário do solo a preferência que the era anteriormente reservada na concessão de Direitos Minerários, garantindo-lhe, porém, indenização por danos e perdas, bem como participação nos resultados da lavra.

Após o novo código e como consequência da abertura de mercado às grandes empresas, a mineração também passou a ser uma opção atrativa para investimentos. Os resultados fizeram-se sentir imediatamente, sobretudo pelo desenvolvimento dos grupos Vale do Rio Doce, então estatal, e do Grupo CAEMI ${ }^{2}$. O minério de ferro assume o papel de alavanca do desenvolvimento.

Na década de 1950, a CVRD consolidou sua posição no mercado mundial. Nas duas décadas seguintes, houve uma diversificação considerável de suas atividades, que passaram a incluir a construção e exploração do porto de Tubarão, próximo a Vitória, ES. Com uma área de atuação a princípio concentrada em torno

\footnotetext{
${ }^{2}$ CAEMI Mineração, nascida em 1942, foi uma das maiores empresas privadas no ramo da mineração no Brasil.
} 
das jazidas de ferro de Minas Gerais, a CVRD com o tempo passou a operar também na região amazônica, onde se localizam as jazidas de Carajás, no sul do Pará.

Em 1997, conforme comprovam várias pesquisas, a Vale era uma empresa rentável e competitiva, mas apesar disto foi privatiza no governo de Fernando Henrique Cardoso. A privatização ${ }^{3}$, como instrumento de descentralização e diminuição do poder do Estado, foi vista como uma marcante tendência da década de 90 "e consistiu no processo de transferência do controle acionário de empresas estatais para o setor privado, visando à diminuição de gastos do governo nos âmbitos federal, estadual e municipal, sob o argumento de tomar a empresa mais competitiva num mercado globalizado". (RUSSO, 2002, p.8)

$\mathrm{E}$, de fato, a Vale, não deixou de crescer após a privatização. O Produto Interno Bruto (PIB) do Brasil, apurado pelo IBGE, em 2014, teve em sua composição a participação da produção mineral no valor de US\$ 40 bilhões. Em termos percentuais isso representa $5 \%$ de todo o PIB nacional. Mas, infelizmente, a sua omissão e negligência e de suas empresas associadas (como a Samarco, responsável pela Barragem do Fundão, da qual a Vale é acionista) permitiu que acontecesse o maior desastre ambiental da história do Brasil, provocado pelo rompimento da Barragem de Fundão, em Mariana, Minas Gerais.

\section{MINERAÇÃO E DESENVOLVIMENTO}

Segundo dados do Ministério do Desenvolvimento, Indústria e Comércio Exterior, MDIC, a produção mineral alça o Brasil a uma posição estratégica de grande relevância no mercado internacional de mineração, sendo esta sustentada por uma numerosa quantidade de jazidas de vários minerais, que se espalham por toda extensão territorial brasileira. No ano de 2012, existiam 8.870 empresas atuando na atividade exploração mineral no Brasil. E que embora as grandes mineradoras sejam mais evidentes, este mercado é formado também por micro e

\footnotetext{
${ }^{3}$ No Brasil, o programa de privatização intensificou-se a partir da criação do Programa Nacional de Desestatização - PND, por meio da Lei 8.031, de 1990, dando prosseguimento ao que já havia sido iniciado em 1979 pelo Programa Nacional de Desburocratização.
} 
pequenas empresas, assim distribuídas: na região Centro-Oeste: 1.075 empresas; Nordeste: 1606; Norte: 515; Sudeste: 3.609; e Sul: 2.065. (DNPM, 2012).

Contabilizando as minas em atividade, a produção brasileira abrange 72 substâncias minerais, dividindo-se da seguinte forma: 23 metálicas; 45 não metálicas e 4 energéticas. Ainda segundo os dados estatísticos, o território brasileiro possui 1.820 lavras garimpeiras; 830 complexos de água mineral e 13.250 licenciamentos. (INSTITUTO BRASILEIRO DE MINERAÇÃO, 2015, p. 8).

Os dados do IBGE sobre o PIB Brasil mostram uma evolução na participação da produção mineral que, segundo o Instituto Brasileiro de Mineração (IBRAM) (2015, p. 24), foi afetada pela queda dos preços das Commodities minerais, e em especial pelo preço do minério de ferro no último ano. Este produto responde por cerca de $75 \%$ da Produção Mineral Brasileira, PMB. Em volume (tonelagem), o Brasil manteve produção de seus bens minerais.

Considerando os números em milhões de US\$, informados pelo Ministério do Desenvolvimento, Indústria e Comércio Exterior, MCDI, Instituto Brasileiro de Geografia e Estatística, IBGE e Instituto Brasileiro de Mineração, IBRAM, entre os produtos de origem mineral, o ferro tem um peso fundamental no saldo da balança comercial: 30.989,30, em 2012; 32.491,50, em 2013; 25.819,10, em 2014 e 14.076,1, em 2015, ao passo que o ouro, que vem em segundo lugar apresenta 2.664,00, em 2012; 2.668,10, em 2013; 2.2322,70, em 2014 e 2.324,6, em 2015.

A Samarco foi a décima segunda maior exportadora do país em 2015, de acordo com o MCDI. As exportações da empresa representaram $1 \%$ do total exportado pelo Brasil em 2015. Sem elas, o déficit da balança comercial brasileira triplicaria no ano de 2015.

Conforme dados da Secretaria do Comércio Exterior, SECEX, do MDIC, o insumo mineral que lidera as exportações na conta de produtos básicos é o minério de ferro, com $11,47 \%$ dos produtos básicos, seguido da soja, com 10,34\%. A importância da produção mineral para economia nacional é flagrante, e sobretudo nos últimos dez anos, foram agregados 232 bilhões de dólares às reservas cambiais brasileiras. (BRASIL, [2016?]). 
Um estudo sobre investimentos em produção mineral da consultoria internacional SNL, publicado na World Exploration Trends (2015), mostra que na questão investimentos em pesquisa mineral de não ferrosos, em 2014, a industrial mundial dedicou cerca de US\$11,4 bilhões, tendo o Brasil ficado em sétimo lugar com os investimentos realizados em seu território, bem distante dos países líderes como Canadá e Austrália. (INSTITUTO BRASILEIRO DE MINERAÇÃO, 2015, p. 13).

No ano de 2014, os investimentos realizados, percentualmente, dividiram-se pelos principais produtores da seguinte forma: Canadá 14\%, Austrália 12\%, Chile $7 \%$, EUA $7 \%$, México $7 \%$ Peru $5 \%$ e Brasil $3 \%$. Pelos dados, percebe-se que há muito espaço para crescimento e diversificação da atividade de exploração mineral no Brasil, requerendo para tanto mais investimentos. Dentre os investimentos realizados pelo setor privado na economia brasileira, a exploração mineral é um dos que recebem mais investidores.

Os números do IBRAM (2015, p. 18) destacam que para o período 2014 a 2018, a estimativa de investimentos é de cerca de US\$ 53,6 bilhões. Os estados Minas Gerais e Pará apresentam-se como principais e maiores destinos dos investimentos: $41,8 \%$ e $21,93 \%$ respectivamente. A diferença para os demais Estados é muito considerável, os quais, juntos, estimam-se receberem um total de $5,53 \%$.

Pelos recursos diversos e dispostos em nosso território, o Brasil é um produtor mineral relevante no mundo e tem nesta capacidade um dos vetores fundamentais da sua economia, sendo possível realizar uma forte expansão desta produção por meio do aumento de investimento em pesquisa e tecnologia.

\section{IMPACTOS NA ECONOMIA LOCAL}

O Estado brasileiro garante as operações e empreendimentos oriundos do comércio de minérios visando à estabilização da economia nacional com exportações do metal, todavia, não se pode deixar de refletir acerca do custo de tal atividade para o meio ambiente. Há a exploração e expropriações do capital sobre o 
trabalho e a natureza, sem se preocupar com os danos causados, como no desastre de Mariana:

As populações atingidas por esse movimento violento e desenfreado [...] buscam empreender esforços na luta por sobrevivência, na disputa por elementos naturais essenciais à vida como terra e água, denunciam violações de que são protagonistas as grandes empresas [...] o que acentua conflitos e embates. (BARROSO; ANGELIM, 2016, p. 13)

O cenário atual da economia de Mariana, MG, mostra que a cidade histórica sempre dependeu e continua dependendo de extrações minerárias, mas, com o acidente, suas arrecadações oriundas dessas operações minimizaram consideravelmente. O Jornal Valor Econômico, em sua edição digital, publicou que após o acidente medidas reparatórias têm sido tomadas pela Samarco. A adesão ao Plano de Demissão Voluntária, PDV, por parte dos funcionários, atingiu o número de 329 profissionais, mas o sindicato dos metalúrgicos de Mariana foi informado de que a empresa pretende cortar 1.200 vagas. (SOUZA, 2016).

O sindicato informou também que a empresa, em junho de 2016, anunciou uma redução de $40 \%$ de mão de obra direta. O número dos funcionários da Samarco era de cerca de 3.000. Esse corte, segundo o jornal, é para atender a uma perspectiva da Samarco em voltar a operar com $60 \%$ de sua capacidade.

Em uma série de reportagens, publicadas no site do G1 sobre Mariana e sobre o distrito de Bento Rodrigues (que foi devastado pela enxurrada de lama tóxica), Fábio Bento das Dores, guia turístico da cidade histórica de Mariana, relata que houve uma queda na chegada de turistas para as cidades históricas da região. A entrevista ainda relata que, segundo a prefeitura de Mariana, a redução no número de turistas é de aproximadamente 30\% (FREITAS, 2016). Já o presidente Antoninho Tavares dos Santos, da Regional Circuito do Ouro da Associação Brasileira da Indústria de Hotéis, $\mathrm{ABIH}$, disse que antes do rompimento da barragem e desde agosto de 2015, já havia uma redução no movimento de turistas por conta da crise política e econômica que o país enfrentava. Segundo ele, os hotéis tinham $45 \%$ de ocupação e com o desastre foi reduzido para $20 \%$. 
Além do turismo, foram impactados pelo desastre da barragem a pecuária, a pesca, a agricultura, o abastecimento de água para a população. O Instituto Brasileiro de Meio Ambiente e dos Recursos Naturais Renováveis, IBAMA, publicou Laudo Técnico Preliminar, cujo documento traz um levantamento dos impactos ambientais decorrentes do rompimento da barragem da Samarco (IBAMA, 2015).

Dentre os pontos críticos do desastre, o laudo técnico traz uma abordagem dos impactos socioeconômicos provocados pela invasão da lama tóxica em uma extensa área por onde ela percorreu após o rompimento da barragem. O documento registra prejuízos nos seguintes serviços públicos: assistência médica, saúde pública e atendimento de emergências médicas; abastecimento de água potável; esgotos de águas pluviais e sistema de esgoto sanitário; limpeza urbana (recolhimento, destinação do lixo); desinfecção habitat; controle de pragas e vetores;geração e distribuição energia elétrica; telecomunicações; transportes locais, regionais e de longo curso; distribuição de combustíveis, especialmente os de uso doméstico; distribuição de combustíveis, especialmente os de uso doméstico; segurança pública, ensino. (IBAMA, 2015, p. 28). Ficaram também prejudicadas as atividades agrícolas, agropecuárias, a produção de subsistência rural, a pesca com a contaminação do Rio Doce. Sem falar do impacto sobre a qualidade da água, fauna e flora da região.

Por seu turno, a Samarco publicou um Dossiê com dados atualizados em 5 de julho de 2016, que traz um balanço de ações executadas para a reconstrução das comunidades atingidas pelo desastre, como as famílias de Bento Rodrigues, cujo povoado foi varrido do mapa. Tal dossiê traz um detalhamento de dados econômicos gerados pela mineradora. Informa que de 2010 a 2014 a Samarco gerou $R \$ 6,3$ bilhões em impostos. Só em 2014 , a empresa pagou $R \$ 1,5$ bilhão. Isto equivale a quase $20 \%$ do que o governo federal espera arrecadar anualmente com a nova CPMF. A expectativa de Arrecadação da CPMF em 4 anos é de 32.000.000. Os impostos pagos pela Samarco e que vão para os cofres das Prefeituras equivalem: impostos Mariana/MG 20.552 (54\% da receita); Impostos Ouro Preto /MG 19.335 (35\% da receita); impostos Anchieta/ES 29.437 (50\% da receita). (SAMARCO, 2016). 
Em síntese, a receita da Samarco equivale a cerca de $6,4 \%$ do PIB do Espírito Santo e 1,5\% do PIB de Minas Gerais. O dossiê também informa acerca dos investimentos da Samarco nos últimos cinco anos (2011 - 2015), em que ela investiu no Brasil $R \$ 9,1$ bilhões, sendo que $R \$ 6,4$ bilhões referem-se ao Projeto da 4 Pelotização. Esse valor é mais do que o Brasil gastou na construção e reforma de todos os estádios para a Copa de 2014, 8,1 bi (2010 a 2014) ou na transposição do rio São Francisco, 8,2 bi (2007 a 2016). (SAMARCO, 2016).

\section{DESENVOLVIMENTO SUSTENTÁVEL}

De modo geral, as informações analisadas no desenvolvimento deste estudo revelam que as atividades de mineração, historicamente, tem impactado o meio ambiente em algumas de suas etapas (extração, produção, distribuição ou consumo). Desta forma, vê-se que os benefícios econômicos têm sobrepujado os cuidados com a natureza. No desastre socioambiental de Mariana, de responsabilidade da SAMARCO S/A, controlada pelos acionistas BHP Biliton Brasil e Vale S.A, observa-se claramente esta falta de cuidados com aspectos ambientais e suas consequências.

A barragem de Fundão, uma das três barragens operada pela Samarco no distrito industrial de Germano, se rompeu no dia 5 de Novembro de 2015. A lama devastou distritos próximos, deixando mortos, feridos e pessoas desabrigadas, tendo chegado ao Rio Doce, e esta assoreou o rio, comprometendo o fornecimento de água potável de diversas cidades da região (D'AGOSTINO, 2015).

No estudo observou-se que na microeconomia os impactos foram rápidos e acentuados, afetando negativamente vários ramos, como o de pesca, agricultura, turismo, comércio entre outras. Outro grande efeito se deu sobre a arrecadação de tributos e impostos, sendo muito sintomático para o governo municipal.

Analisando os dados macroeconômicos levantados durante este estudo, foi identificado que, no período anterior à tragédia de Mariana (Janeiro a Outubro de 2015), a Samarco exportou US $\$ 1,85$ bilhão, o que corresponde a $1,15 \%$ do total de exportações do Brasil, sendo responsável por mais de $15 \%$ do minério de ferro 
exportado. Observando-se o período pós-tragédia, a balança comercial, no curto prazo, não foi impactada pela parada de produção da SAMARCO, pois as mineradoras concorrentes, que possivelmente se encontravam com bom nível de estoque, supriram o espaço deixado por ela.

Ainda está por se confirmar, com números do PIB do primeiro semestre de 2016 (IBGE), a expectativa de impactos causados pela parada de produção da SAMARCO e consequente efeitos na balança comercial.

Outra verificação a ser realizada no PIB 2016 são os possíveis impactos associados a outros efeitos da tragédia e consequentes perdas na indústria de exploração mineral, o que neste momento não é possível determinar, somente especular, pois os números do PIB do primeiro semestre ainda não foram divulgados.

O estudo demonstra que na macroeconomia, possíveis efeitos do desastre ainda não puderam ser identificados e mensurados. Entretanto, faz-se imprescindível considerar a relevância dos insumos minerais para o crescimento e desenvolvimento socioeconômico do país, uma vez que estão presentes nos mais diversos produtos que circulam no mercado consumidor global, desde simples utensílio doméstico, passando por eletrodomésticos, equipamentos eletrônicos, automóveis, até itens de altíssima tecnologia, fazendo parte do dia a dia na vida das populações.

Destaca-se que o Brasil, conforme apurado pelo estudo, é um produtor mineral relevante no mundo. Desta capacidade consiste um dos vetores fundamentais da sua economia, o que lhe permitirá realizar uma forte expansão da produção caso aumente os investimentos em pesquisa e tecnologia e paute a realização da atividade em processos centrados na sustentabilidade. Pois, conforme indicado pelo estudo, mesmo sem a confirmação dos impactos sobre a macroeconomia ainda não terem sido apurados, um dos principais motivos para a causa da tragédia foi o desrespeito ao meio ambiente através da busca por menores custos e maior lucratividade, desconsiderando a preocupação também com as vidas humanas perdidas e desabrigadas. 
Neste contexto, vale relembrar que os primeiros pensamentos a respeito do desenvolvimento sustentável ressaltavam a importância do crescimento econômico, rejeitando a ideia de crescimento zero como forma de melhoria socioambiental, uma vez que entendia-se que as condições de vulnerabilidade social e o desrespeito ambiental se agravariam sem o acesso a renda, estimulando-se o crescimento a qualquer custo. (SACHS, 2002, p. 52)

Porém, o raciocínio fundamentado na lógica de mercado configurou-se incompatível com o pensamento do desenvolvimento sustentável, especialmente após a conferência de 1972 das Nações Unidas, que inseriu na agenda internacional a dimensão do meio ambiente promovendo: "a crítica ao crescimento selvagem e a análise de seus custos sociais e ambientais". (SACHS, 2002, p.54)

Desta forma, posteriormente, compreendeu-se que: "o uso produtivo não necessariamente precisa prejudicar o meio ambiente ou destruir a diversidade, se se tiver consciência de que todas as nossas atividades econômicas estão solidamente fincadas no ambiente natural." (SACHS, 2002, p, 32)

\section{CONSIDERAÇÕES FINAIS}

A tragédia que se abateu sobre esta localidade, abre espaço para propostas de endurecimento da legislação por meio do licenciamento ambiental, seja na concessão ou em sua renovação, para tentar impedir acontecimentos como estes. Entretanto, o processo de licenciamento ambiental, por si só, já é extremamente moroso, fato que de costume implica em atrasos significativos na liberação de obras relevantes para a ampliação da produção. Assim, questiona-se até que ponto esse enrijecimento comprometeria a capacidade produtiva das corporações, inviabilizando a geração e distribuição da renda.

Por outro lado, tramita no Congresso Nacional a Proposta de Emenda Constitucional PEC 65/2012, a qual objetiva, principalmente, dar celeridade à conclusão das obras tanto públicas quanto privadas. Justifica-se que desta forma os políticos eleitos conseguiriam propor e concluir obras dentro de seus mandatos, além de permitir que a iniciativa privada não perca a competitividade visto que se 
combateria ações ditas "protelatórias" de grupos contrários ao desenvolvimento econômico. Contudo, esta proposta busca, nitidamente, atender a interesses econômicos e de grupos específicos da sociedade, os quais em momentos de alta do desemprego, necessidade de aumento da produção, acirramento da competição internacional, encontram adeptos imediatistas ávidos pelo encerramento da recessão a qualquer custo (SENADO, 2012).

Estas duas dicotômicas abordagens traduzem uma luta de ideologias em que os defensores da conservação ambiental saem perdendo quase sempre.

A esse respeito, Sachs (2002, pp. 53-55) afirma que: "os mercados são por demais míopes para transcender os curtos prazos e cegos para quaisquer considerações que não sejam lucros e eficiências smithiana de alocações de recursos." O que de fato constata-se. Porém, essa miopia neoliberal que somente enfatiza os ganhos a curto prazo, justificando-se pelo aumento dos indicadores econômicos, precisa ser fortemente combatida, pois, quando enfatizada, em geral, acabam por menosprezar aspectos socioambientais tão importantes quanto os financeiros, provocando desastres como o da barragem do Fundão em Mariana, desconstruindo toda a relevância econômica da atividade alcançada ao longo dos anos. Assim: "de modo geral, o objetivo deveria ser o do estabelecimento de um aproveitamento racional e ecologicamente sustentável da natureza em benefício das populações locais." (SACHS, 2002, p. 53-55)

Devido à complexidade do tema e dificuldade de apuração dos dados in loco, considera-se que este estudo é inconclusivo, sugerindo-se ampliação de sua base de dados para efetividade nas análises. Como possibilidade para os próximos estudos, propõe-se análises evolutivas do cenário econômico de modo que seja possível identificar se o programa de recuperação proposto pela empresa e algumas entidades públicas surtiu efeito.

\section{REFERÊNCIAS}

BARROSO, Milena; ANGELIM, Yanne. A construção de barragens no Brasil como estratégia de reprodução do capital. In: ENCONTRO NACIONAL DE POLÍTICA SOCIAL, 11., 2016, Vitória. Anais..., Vitória, 2016. 
BRASIL. Ministério da Indústria, Comércio Exterior e Serviços. Balança comercial registra superávit de U\$ 23,6 bilhões no primeiro semestre. [2016?]. Disponível em: <http://www.mdic.gov.br/component/content/article?id=1651>. Acesso em: 15 jul. 2016.

Senado. Proposta de Emenda à Constituição n 65, de 2012.

Disponível em: <https://www25.senado.leg.br/web/atividade/materias//materia/109736>. Acesso em: 15 jul. 2016. Agenda Brasil 2015.

BRUM, Argemiro Jacob. O desenvolvimento econômico brasileiro. 29. ed. Petrópolis: Vozes: Ed. Unjuí, 2012.

D'AGOSTINO, R. Rompimento de barragem em Mariana: perguntas e respostas.

G1 Globo.com, São Paulo, 13 nov. 2015. Ciência e Saúde. Disponível em: <http://g1.globo.com/ciencia-e-saude/noticia/2015/11/rompimento-de-barragens-emmariana-perguntas-e-respostas.html>. Acesso em: 14 jul. 2016.

FAUSTO, Boris. História do Brasil. 13. ed. São Paulo: EDUSP, 2010.

FREITAS, Raquel. Seis meses após o desastre, turismo em Mariana ainda sofre reflexos. Globo, Minas Gerais, 05 mai. 2016. Disponível em:

<http://http://g1.globo.com/minas-gerais/desastre-ambiental-emmariana/noticia/2016/05/seis-meses-apos-desastre-turismo-em-mariana-ainda-sofrereflexos.html> Acesso em: 15 jul. 2016.

IBAMA. Laudo técnico preliminar: impactos ambientais decorrentes do desastre envolvendo o rompimento da barragem de Fundão, em Mariana, Minas Gerais.

Brasília: IBAMA, 2015. 38 p.

INSTITUTO BRASILEIRO DE MINERAÇÃO. Informações sobre a economia mineral brasileira 2015. Brasília, DF, 2015. Disponível em:

<http://www.ibram.org.br/sites/1300/1382/00005836.pdf>. Acesso em: 20 jul. 2016. Apresenta dados estatísticos sobre a economia mineral brasileira.

RUSSO, Fátima Ferreira. Privatização da Vale do Rio Doce: valores, manifestações e implicações. 2002. 91 f. Dissertação (mestrado em Administração Pública)-Fundação Getúlio Vargas, Rio de Janeiro, 2002. Disponível em: <bibliotecadigital.fgv.br/dspace/bitstream/handle/10438/3567/000312977.pdf?...1> Acesso em: 20 jul. 2016.

SILVA, Olinthio Pereira da. A mineração em Minas Gerais: passado, presente e futuro. Geonomos, Belo Horizonte, v. 3, n. 1, 1995. Disponível em: <http://www.igc.ufmg.br/portaldeperiodicos/index.php/geonomos/article/view/217>. Acesso em: 16 jul. 2016. 
SACHS, I. Caminhos para o desenvolvimento sustentável. Rio de Janeiro: Garamond, 2002.

SAMARCO. Dossiê Samarco - Balanço das ações. Belo Horizonte, 2016.

Disponível em: <http://www.samarco.com/balanco/>. Acesso em: 20 jul. 2015. Dados atualizados em 05 de julho de 2016.

SAMARCO pela quinta vez ganha "Melhores e Maiores" da Exame. Brasil Mineral, São Paulo, 2 jul. 2015. Mineração. Disponível em:

$<$ http://www.brasilmineral.com.br/noticias/samarco-pela-quinta-vez-ganha$\%$ E2\%80\%9Cmelhores-e-maiores\%E2\%80\%9D-da-exame>. Acesso em: 10 out. 2016.

SOUZA, Marcos de Moura e. Adesão a PDV da Samarco é um pouco mais de um quarto da meta. Valor Econômico, Belo Horizonte, 06 jul. 2016. Disponível em: <http://www.valor.com.br/empresas/4626583/adesao-pdv-da-samarco-e-de-umpouco-mais-de-um-quarto-da-meta>. Acesso em: 10 jul. 2016.

VALE S.A. Departamento de Comunicação Corporativa (DICl). Vale: nossa história. Rio de Janeiro: Verso Brasil Editora, 2012. 